\title{
What lies beneath? Molecular evolution during the radiation of caecilian amphibians
}

\author{
María Torres-Sánchez ${ }^{1,2^{*}}$ D, David J. Gower ${ }^{3}$, David Alvarez-Ponce ${ }^{4}$, Christopher J. Creevey ${ }^{5}$, Mark Wilkinson ${ }^{3}$ and \\ Diego San Mauro ${ }^{1}$
}

\begin{abstract}
Background: Evolution leaves an imprint in species through genetic change. At the molecular level, evolutionary changes can be explored by studying ratios of nucleotide substitutions. The interplay among molecular evolution, derived phenotypes, and ecological ranges can provide insights into adaptive radiations. Caecilians (order Gymnophiona), probably the least known of the major lineages of vertebrates, are limbless tropical amphibians, with adults of most species burrowing in soils (fossoriality). This enigmatic order of amphibians are very distinct phenotypically from other extant amphibians and likely from the ancestor of Lissamphibia, but little to nothing is known about the molecular changes underpinning their radiation. We hypothesised that colonization of various depths of tropical soils and of freshwater habitats presented new ecological opportunities to caecilians.
\end{abstract}

Results: A total of 8540 candidate groups of orthologous genes from transcriptomic data of five species of caecilian amphibians and the genome of the frog Xenopus tropicalis were analysed in order to investigate the genetic machinery behind caecilian diversification. We found a total of 168 protein-coding genes with signatures of positive selection at different evolutionary times during the radiation of caecilians. The majority of these genes were related to functional elements of the cell membrane and extracellular matrix with expression in several different tissues. The first colonization of the tropical soils was connected to the largest number of protein-coding genes under positive selection in our analysis. From the results of our study, we highlighted molecular changes in genes involved in perception, reduction-oxidation processes, and aging that likely were involved in the adaptation to different soil strata.

Conclusions: The genes inferred to have been under positive selection provide valuable insights into caecilian evolution, potentially underpin adaptations of caecilians to their extreme environments, and contribute to a better understanding of fossorial adaptations and molecular evolution in vertebrates.

Keywords: Ecological opportunity, Gene ontology, Gymnophiona, Positive selection signatures, Vertebrate evolution

\section{Background}

Understanding the diversity of life and how species have evolved into their different and specialized forms is an ultimate goal of evolutionary biology. The events that lead to macroevolutionary diversification by adaptive

\footnotetext{
* Correspondence: torressanchez.maria@gmail.com

'Department of Biodiversity, Ecology and Evolution, Complutense University of Madrid, 28040 Madrid, Spain

2Present address: Department of Neuroscience, Spinal Cord and Brain Injury Research Center \& Ambystoma Genetic Stock Center, University of Kentucky, Lexington, KY 40536, USA

Full list of author information is available at the end of the article
}

radiation have been related to ecological opportunities: the availability of new ecological resources for exploitation [1-3]. The potential for ecological opportunities to trigger adaptive radiation (diversification of species from a common ancestor into different ecomorphological forms) is widely recognised (e.g. [4-8]). Phenotypic evolutionary changes accumulated during adaptive radiations ultimately have a molecular basis that can involve a variety of genetic changes, including gene gain and loss, beneficial mutations, regulatory changes or other innovations [9-11]. As more genomic data becomes

(c) The Author(s). 2019 Open Access This article is distributed under the terms of the Creative Commons Attribution 4.0 International License (http://creativecommons.org/licenses/by/4.0/), which permits unrestricted use, distribution, and reproduction in any medium, provided you give appropriate credit to the original author(s) and the source, provide a link to the Creative Commons license, and indicate if changes were made. The Creative Commons Public Domain Dedication waiver (http://creativecommons.org/publicdomain/zero/1.0/) applies to the data made available in this article, unless otherwise stated. 
available, a better understanding of the evolutionary mechanisms underpinning biodiversity should follow. Molecular evolutionary processes can be investigated by studying regulatory and/or functional elements of genomes. In protein-coding genes, sources of evolutionary variation can be explored by comparing rates of nucleotide substitutions at synonymous $(\mathrm{dS})$ and non-synonymous $(\mathrm{dN})$ sites; substitutions in those latter sites result in a change of amino acid sequence and consequently can result in change of phenotype. The ratio between these rates, $\omega(\omega=\mathrm{dN} / \mathrm{dS})$, provides a widely used means of identifying selective pressures in proteins [12].

Adaptive radiation of vertebrates is in part explained by genetic changes that allowed new functions to emerge [1315], increasing the fitness of the organisms in new environments. One of these environments, the soil, presents several restrictive conditions, including low levels of light, high resistance to locomotion, low airborne transmission of sound and scent, and low oxygen $\left(\mathrm{O}_{2}\right)$ and high carbon dioxide $\left(\mathrm{CO}_{2}\right)$ levels (hypoxia and hypercapnia respectively). In addition, many microorganisms (fungi, protozoans, bacteria) and diverse invertebrates (often pathogenic) abound in especially humid and thermally stable soils [16]. Despite these challenges, several groups of vertebrates are well adapted to life in soil [17-19], including one of the most ancient lineages of extant terrestrial vertebrates, the caecilian amphibians that radiated in the edaphic environment during the early Mesozoic [20, 21]. Caecilians (order Gymnophiona) are limbless, elongate, mostly tropical amphibians. Adults of most species burrow in soil. Many other extant amphibians spend time in soil but feed and breed above ground [22, 23]. In contrast, many adult terrestrial caecilians are highly fossorial, dedicated burrowers that feed and breed within moist soils [24]. Terrestrial caecilians inhabit different layers of soil, from leaf litter to deeper strata, while species of one family (Typhlonectidae) are secondarily semi- or fully aquatic [22]. Caecilian evolution has clearly involved the colonisation of tropical soils. We hypothesise that, as well as providing distinctive challenges, the soil offered new ecological opportunities to caecilians with new resources and absence of, or reduction in, competitors and predators, perhaps similar to emergent islands [25-28], newly formed lakes [29, 30], and post-mass extinction environments [31, 32] for other organisms. Regions with high above-ground biodiversity, such as the tropics, exhibit low below-ground biodiversity [33] where caecilians might have encountered lower competitive pressure. In addition of the suggestive reduced competition, soil is potentially more stable and less subject to harmful fluctuations in humidity and temperature. Ancestral caecilians adapted to life in soil, developed important innovations and diversified. Given that fossoriality is a derived condition among amphibians, several morphological features of caecilians are clearly adaptations to life in soil, some of which are shared convergently with other edaphic animals. These include modified skull architecture for head-first burrowing and feeding underground [34], elongated limbless bodies with modified axial musculature [35, 36], reduced visual and hearing systems, and novel sensory tentacles [37-39]. The molecular changes underlying the evolutionary origin and diversification of caecilians remain unexplored thus far. In this study, we investigated molecular processes involved in the exploitation of (i) soil surface habitats, (ii) deeper soil habitats, and (iii) freshwaters and associated muds.

Recently, reference transcriptomes for several species of caecilians have been generated $[21,40]$, providing an opportunity to explore genomic changes in caecilian amphibians. Here, we analyse the protein-coding sequences from transcriptome data for nine different tissue types (foregut, heart, kidney, liver, lung, muscle, skin, spleen, and testis) of five species of Neotropical caecilians [40] that occur in a range of habitats (DJG, MW, DSM pers. obs.). The semi-fossorial species Rhinatrema bivittatum (Guérrin-Méneville, 1838) is encountered mostly in more superficial layers of soils as well as on the surface after heavy rain. Caecilia tentaculata Linnaeus, 1758 appears to be a much stronger burrower based on its more heavily ossified skull [34], but it is also encountered on the surface after heavy rains. Typhlonectes compressicauda (Duméril \& Bibron, 1841) is a fully aquatic species that can burrow in soft substrates. Microcaecilia unicolor (Duméril, 1861) and $M$. dermatophaga Wilkinson, Sherratt, Starace \& Gower, 2013 are more dedicated burrowers not seen on the surface and mostly found in deeper layers of the soil. The sampled caecilians include species from both sides of the basal divergence within Gymnophiona belonging to four of the ten currently described families $[41,42]$ of the order (Rhinatremidae, Typhlonectidae, Siphonopidae and Caeciliidae), and their phylogenetic history encompasses several major shifts in caecilian evolution. We have compared nucleotide substitution rates of candidate groups of orthologous protein-coding genes for these five caecilian species in order to identify genes that potentially have, at some time, been under positive selection. The sampled caecilians allow us to explore nine different branches of the caecilian tree of life (Fig. 1) covering the evolutionary periods in which caecilians first adapted to life in soil, and subsequently adapted to deeper soils and to aquatic environments. We identified signatures of positive selection in several protein-coding genes on all branches. Some of these candidate genes could be involved in the adaptive radiation of caecilian amphibians, plausibly in the adaptation to fossoriality, and in the evolution of their special innovative traits.

\section{Results}

We identified 8540 candidate groups of one-to-one orthologous protein-coding sequences (ranging in size 


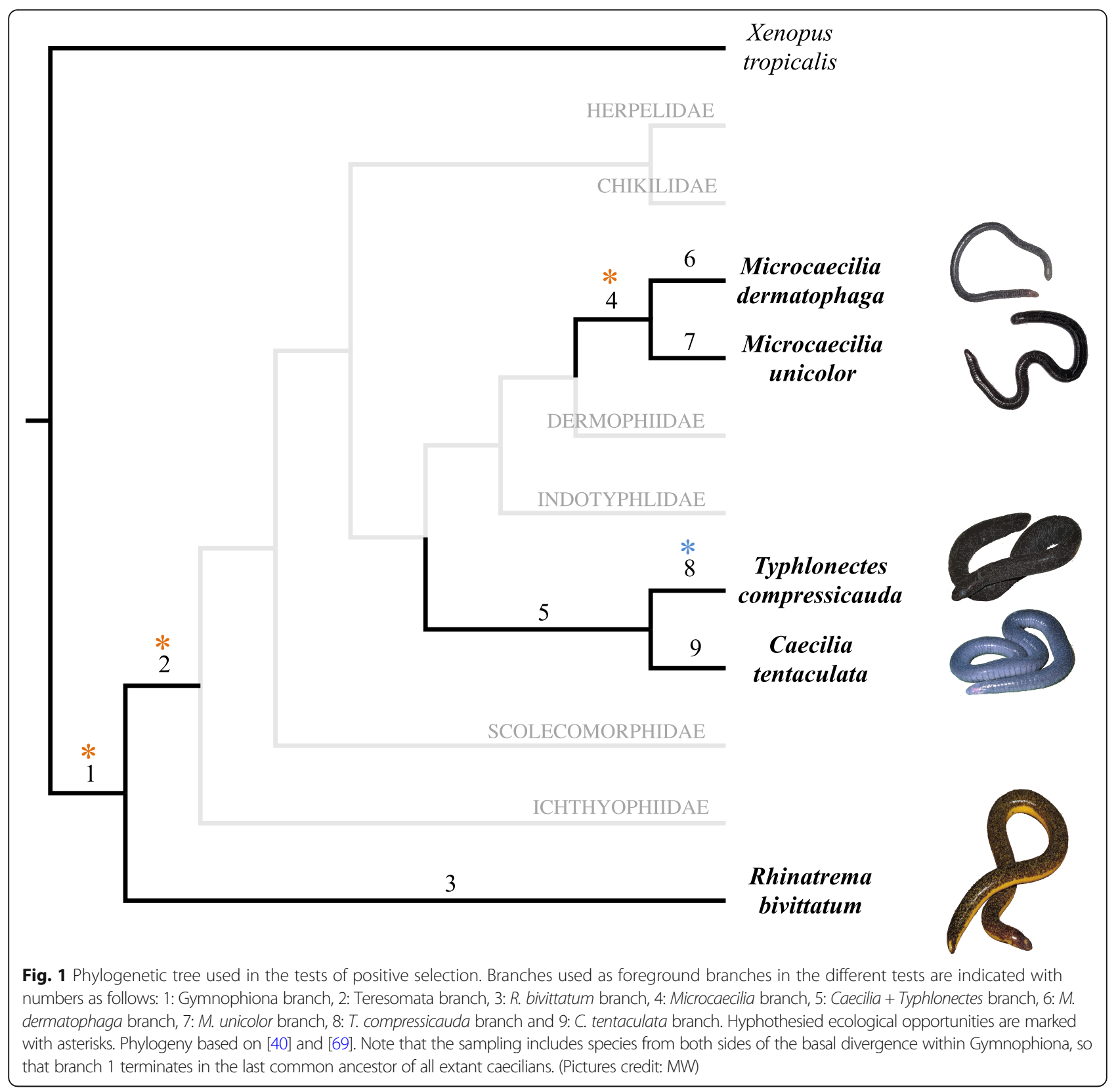

from 138 to $94,440 \mathrm{bp}$ ) among the sampled caecilian species ( $R$. bivittatum, C. tentaculata, T. compressicauda, $M$. unicolor and $M$. dermatophaga) and the frog outgroup (Xenopus tropicalis Gray, 1864). Through branch-site model comparisons, we detected 168 genes with signals of potential adaptive molecular evolution along the nine sampled branches (Fig. 1) of the caecilian evolutionary tree. From the identified sites (the fraction of codons with $\omega>1$ ) in those 168 genes, we found an overall $4.39 \%$ of the codons under positive selection at contiguous positions, which were mainly located in genes with a large number of codons involved in the signature of selection. All the alignments of the 168 genes with signatures of positive selection presented a GUIDANCE2 alignment score higher than 0.96 with the exception of one alignment with a value of 0.924565 (ENSXETG00000018913; see Additional file 1: Table S1 column GUIDANCE2 alignment score). The alignment confidence scale of the GUIDANCE2 showed a high confidence in the great majority of the analysed sites of our alignments (95.45\% of the sites present the maximum alignment confidence value). We characterized the genes with evidence of sites under positive selection using the functional annotation of their homologous genes in $X$. tropicalis. These annotations are summarized numerically in Table 1 (see Additional file 1: Table S1 for more details). 
Table 1 Number of genes under positive selection

\begin{tabular}{|c|c|c|c|c|c|c|c|}
\hline $\begin{array}{l}\text { Foreground } \\
\text { branch }\end{array}$ & $\begin{array}{l}\text { Branch } \\
\text { number }\end{array}$ & $\begin{array}{l}\text { Genes under positive } \\
\text { selection (FDR < 10\%) }\end{array}$ & $\begin{array}{l}\text { Genes with } \\
\text { description }\end{array}$ & $\begin{array}{l}\text { Genes } \\
\text { with GO }\end{array}$ & $\begin{array}{l}\text { Biological } \\
\text { process domains }\end{array}$ & $\begin{array}{l}\text { Molecular } \\
\text { function domains }\end{array}$ & $\begin{array}{l}\text { Cellular } \\
\text { component } \\
\text { domains }\end{array}$ \\
\hline Gymnophiona & 1 & 50 & 47 & 43 & 96 & 84 & 75 \\
\hline Teresomata & 2 & 8 & 8 & 7 & 13 & 16 & 16 \\
\hline Rhinatrema bivittatum & 3 & 17 & 17 & 15 & 31 & 29 & 22 \\
\hline Microcaecilia & 4 & 13 & 12 & 11 & 34 & 33 & 19 \\
\hline Caecilia + Typhlonectes & 5 & 15 & 14 & 15 & 28 & 35 & 19 \\
\hline Microcaecilia dermatophaga & 6 & 33 & 30 & 31 & 74 & 72 & 44 \\
\hline Microcaecilia unicolor & 7 & 16 & 15 & 15 & 48 & 56 & 28 \\
\hline Typhlonectes compressicauda & 8 & 18 & 17 & 16 & 34 & 32 & 27 \\
\hline Caecilia tentaculata & 9 & 7 & 7 & 7 & 23 & 15 & 16 \\
\hline
\end{tabular}

The vast majority of the genes inferred to have been positively selected (153 genes) were associated with gene ontology (GO) terms that involve: 247 out of 4301 biological processes annotated in $X$. tropicalis, 74 out of 856 cellular components, and 170 out of 2041 molecular functions (Table 1 and Additional file 1: Table S1). A total of nine of those genes with GO information were classified as novel or uncharacterised without gene description in the Ensembl database. For these nine genes (sult1c1, col16a1, slc18a1, ano9, fr47, plg, tmprss2, pacsin1, and inmt; see Additional file 1: Table S1) further information was retrieved from the Non-redundant protein sequences database. GO information for biological process domains of the positive selected genes was gathered for the nine sampled branches of the caecilian evolutionary tree. A total of 47 general categories were created from the summarized GO terms of the REVIGO exploratory networks using semantic connectivity of the GO terms [43]. In Fig. 2 the relative number of different GO terms is used as a proxy for the number of genes under a general biological processes; these are symbolized to show the different processes for which positive selected genes are involved for each branch. Despite the semantic connectivity, no functional enrichment and protein-protein interactions (PPIs) were found within any of the sets of genes under positive selection on each branch, and only one association network on the Gymnophiona branch presented evidence (although not statistically significant) of functional enrichment linked to four genes considered to be involved in extracellular matrix (ECM) interactions (Fig. 3). GO terms of cellular component domains, which reflect subcellular location, related to cellular membrane and ECM elements (membrane [GO:0016020], integral component of membrane [GO:0016021], ECM [GO:0031012], extracellular region [GO:0005576], extracellular space [GO:0005615] and proteinaceous ECM [GO:0005578]) were the most common terms assigned to the positively selected genes. Many of these genes are also associated with extracellular processes, transmembrane signaling and transport terms of the biological process GO domain (see biological process categories: Receptor signaling, Synaptic communication, Signal transduction, Transmembrane transport and electrochemical equilibrium, and Vesicular traffic in Fig. 2; and find further information in the Additional file 1: Table S1). Finally, functional characterization of the genes under positive selection was completed with caecilian tissue expression information available for nine different tissue types (for detailed information see Additional file 1: Table S1 Tissue expression column). Only five of the genes with signatures of positive selection showed tissue specificity expression (col17a1 with more than $95 \%$ of its Transcripts Per Million (TPM) in the skin; tmem 27 in the kidney; and $f 2$, $k l k b 1$ and $p l g$ in the liver).

Just two of the nine studied branches of the phylogeny account for almost $50 \%$ of the identified signatures of positive selection: the branch subtending the clade comprising all sampled caecilians, hereafter the "Gymnophiona branch" (branch 1 in Figs. 1, 50 genes, 29.58\%: acot2, wdr1, slc34a2, sod3, col4a2, akr1a1, als2cl, nup155, c10orf35, ddx17, adamts7, nckipsd, esyt1, msn, aqp9, slc22a31, rph3a, lamc1, tet2, gstcd, nup153, gdpd5, tacc2, klhdc10, golga1, pigr, gigyf1, cul9, cdhr2, hprt1, cgn, itga3, p2ry11, ptprh, SPEN, qSox1, vwf, cdk12, tbrg4, tcf19, spg11, rps13, gsto2, tnrc6a, cp, col17a1, acadvl, sult1c1, col16a1 and slc18a1; see Additional file 1: Table S1), and the terminal branch subtending $M$. dermatophaga (branch 6 in Figs. 1, 33 genes, 19.52\%). There are significantly more genes with a signal of positive selection on the terminal branches subtending $M$. dermatophaga and $T$. compressicauda than on the terminal branches subtending their respective sister species in the sampled phylogeny (Microcaecila sister group: branches 6 and 7, Typhlonectes-Caecilia sister group: branches 8 and 9, with two-tailed binomial tests $p$-values 0.021 and 0.043 respectively). Different proportions of genes under positive selection were found also associated with 


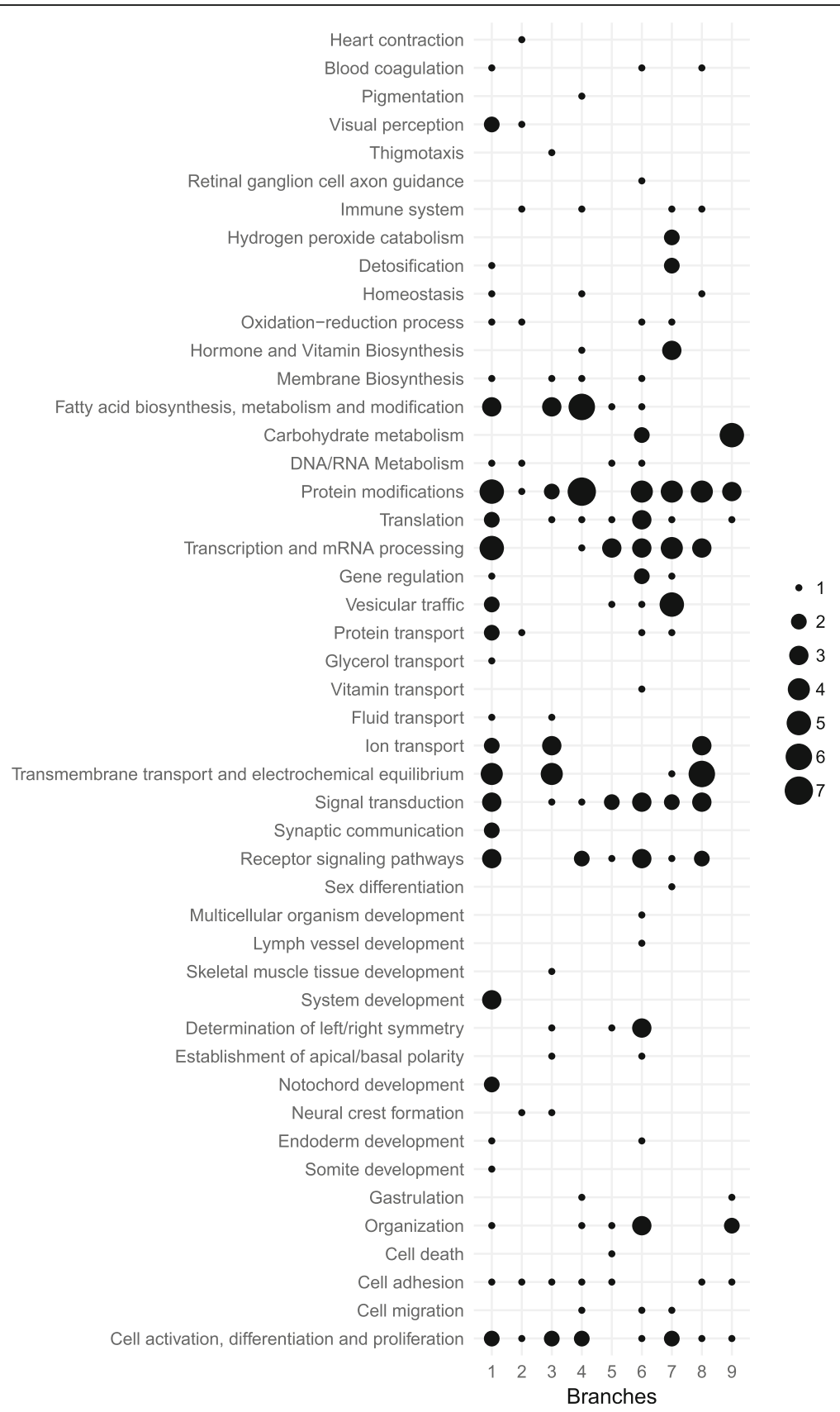

Fig. 2 General categories of biological processes from gene ontologies (GO) related to the genes under positive selection. For each of the sampled branches, the relative number of different annotated GO terms (a proxy of the number of identified genes under positive selection) under a general biological processes is symbolized by the different circle sizes (see legend)

branches (branches 1, 2, 4 and 8 in Fig. 1) that represent hypothesized ecological opportunities. Some of these positive selected genes in the four above-mentioned branches could have been involved in the adaptation to the new edaphic environments that caecilians were colonising. In addition to the 50 genes on the Gymnophiona branch, that is related to the initial hypothesized ecological opportunity in soil surface habitats, we found eight genes (fam3b, aoc3, mbd5, hgs, masp1, pcdh7, tnc, and sypl1; see Additional file 1: Table S1) with signatures of positive selection $(5.32 \%$ of the total of genes with signatures of positive selection in this study) on the branch in which the hypothesized conquest of deeper soil habitats might have happened (branch 2, Fig. 1 hereafter "Teresomata branch"). The adaptation to freshwater habitats and associated muds that occurred on the branch subtending T. compressicauda (branch 8 in Fig. 1) could have been mediated by some of the 18 genes 


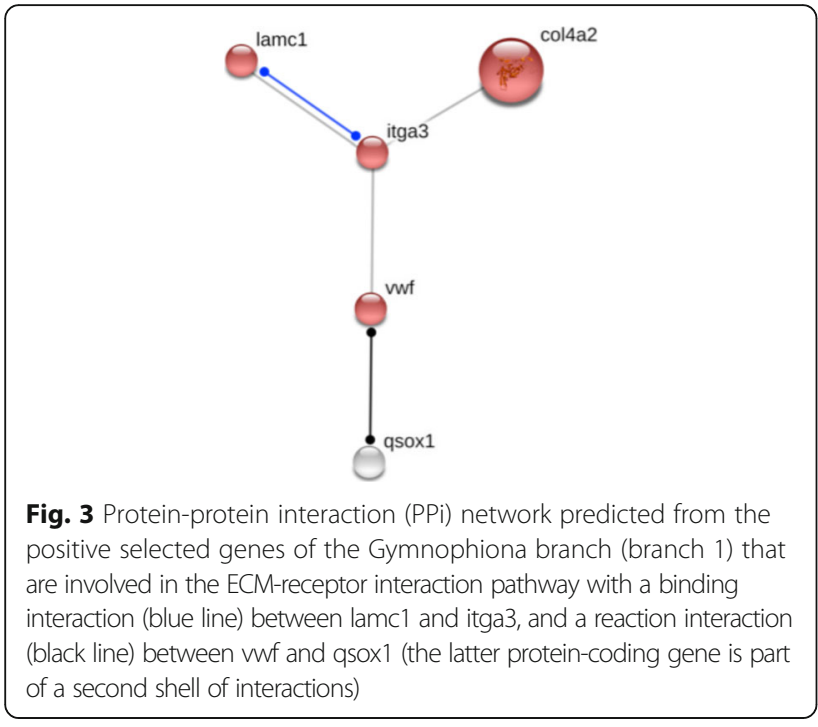

under positive selection on this branch (f2, col4a1, slc30a10, camkmt, klkb1, mios, polr2a, prkag3, cwc22, ate1, myh4, thoc5, arhgap33, clcn3, fam13a, adgrg6, $d s g 2$, and fr47; see Additional file 1: Table S1). Finally, adaptation to more extreme fossoriality linked to the branch subtending Microcaecilia (branch 4 in Fig. 1, hereafter "Microcaecilia branch") could have been facilitated by some of the 13 genes (pinx1, col4a2, fam $3 b$, iqsec2, ddx24, mrps7, elovl5, ca5b, yes1, basp1, tspan36, acp1, and plg; see Additional file 1: Table S1) with signatures of positive selection $(7.73 \%$ of the total of genes with signatures of positive selection in this study) on this Microcaecilia branch.

Finally, several of the positively selected protein-coding genes might be related (potentially causally) to unique traits of caecilian amphibians beyond their adaptations to the four hypothesised new environments. Among them, six protein-coding genes annotated as collagen chains were found to bear evidence of positive selection on several branches (col4a2 on the Gymnophiona and the Microcaecilia branches; col17a1 and col16a1 on the Gymnophiona branch; coltal on the $T$. compressicauda branch; col12a1 on the M. dermatophaga and the M. unicolor branches; and col5a2 on the R. bivittatum and the M. unicolor branches; see Additional file 1: Table S1); nine genes related to lipid metabolism and fatty acid metabolism (acot2 on the Gymnophiona branch; gdpd5 on the Gymnophiona branch; plpp1 on the R. bivittatum branch; elovl5 on the Microcaeclia branch; sptlc3 on the M. unicolor branch; cyp17a1 on the M. unicolor branch; lcat, asah1, and cers6 on the $M$. dermatophaga branch; see Additional file 1: Table S1, and biological process category: Fatty acid biosynthesis, metabolism and modification in Fig. 2); and at least five components involved in immune system and related mechanisms (tet2 on the
Gymnophiona branch; masp1 on the Teresomata branch; enpp3 on the Caecilia + Typhlonectes branch; yes1 on the Microcaecilia branch; fyn on the M. unicolor branch; see Additional file 1: Table S1, and biological process category: Immune system and Homeostasis in Fig. 2).

\section{Discussion}

General view of caecilian molecular evolution

Our analyses identified 168 protein-coding genes with signatures of having been under positive selection at least once during the evolution of caecilians. The reliability of the selection signals is supported by the adequacy of the alignments, quantified by the GUIDANCE2 alignment score [44], and the small proportion of adjacent codons with $\omega>1$, which endorse the independence of the nucleotide changes that is required by the applied selection tests [12]. The identified genes represent only $1.97 \%$ of the total surveyed genes, a small proportion compared with studies of other taxa [45-47], and presented a lack of connectivity that perhaps reflects lack of knowledge about the identified genes [43]. These 168 candidate genes under positive selection are almost certainly a substantial underestimate due to our conservative selection of orthologous sequences (only those present in every species, including $X$. tropicalis; no paralogs within species; and stringent filtering; see Methods section) intended to reduce false positives caused by alignment artefacts, to which positive selection inference methods are known to be sensitive [48]. We also are probably missing signal from genes whose evolution history is not congruent with the species tree topology [49]. An additional source of underestimation in the detection of positive selection could come from genes that are saturated [50].

Valuable insights into the molecular evolution of caecilians can be extracted from the functional annotations of the genes bearing signatures of positive selection. The high prevalence of $\mathrm{GO}$ terms related to cell membrane and its integral components in the set of genes with signatures of positive selection seems to underline the important role of the membrane components during the evolution of caecilian amphibians, and is consistent with positive selection signals found in other species of vertebrates [51,52] and with previously identified regulatory innovations related to extracellular signaling in the evolution of other major tetrapod groups [53]. Molecular changes in functional elements of the cell membrane and the ECM are likely an additional important genetic aspect of vertebrate macroevolution.

\section{Ancient genetic toolkit for caecilians}

The evolutionary changes on the Gymnophiona branch occurred subsequent to the divergence of caecilians from the other extant amphibians, leading to the last common ancestor of all extant caecilians. During this period in 
evolution, caecilian ancestors would have started to colonise soil environments and exploit the ecological opportunities they provided, and we would expect molecular changes linked to fossorial adaptation. From the 50 genes with signatures of positive selection that are involved in 96 biological processes based on their GO annotation grouped in 28 general categories (Table 1, Fig. 2 and Additional file 1: Table S1), we highlight the identified genes involved in development-related processes (lamc1, tet2, nup153, tacc2, spg11, see Additional file 1: Table S1 and Fig. 2); and in oxidation-reduction (redox) processes (sod3, akrla1, qsoxl, $c p$, see Additional file 1: Table S1 and Fig. 2).

Related to development, one of the candidate genes deserves special mention, a component of the extracellular glycoprotein matrix of the membrane, the laminin subunit gamma 1 (lamc1), which is essential for basement membrane assembly during mice embryogenesis [54-56]. The lamc1 gene is associated with several development and morphogenesis processes (GO:0007420, GO:0048854, GO:0048731, and GO:0061053). Additionally, lamc1 is one of the four elements of the detected functional gene-network (Fig. 3). Its function is linked to ECM interaction mechanisms [57], such as cell adhesion and cell-to-cell communication (ECM-receptor interaction: KEEG pathway ID 04512; see Fig. 3). Among other functions, lamc1 is related to light perception (GO:0050908), retinal and eye development (GO:0031290, GO:0001654, respectively), and optokinetic behavior (GO:0007634). The gene lamc1 has also been related to mechanosensitive processes in zebrafish [58] and studied as part of a set of important genes for perception in mammals [59]. Unlike other extant amphibians, caecilians are rod-only monochromats with small eyes covered by skin and sometimes also bone [60]. Light is not only important for visual perception, but also plays other important roles controlling, for example, the circadian rhythms vital for synchronization of biological cycles [61]. We hypothesize that molecular innovation in lamc1 might be involved in sensorial adaptation, perhaps related to circadian rhythms, in underground environments.

Oxidation-reduction (redox) processes are associated (by GO terms) with four protein-coding genes inferred to be under positive selection on the Gymnophiona branch. Environmental conditions could have driven the emergence of molecular changes to tolerate chronic low $\mathrm{O}_{2}$ and high $\mathrm{CO}_{2}$ levels that characterise soils [16]. At higher concentrations, $\mathrm{CO}_{2}$ is converted to acid by ionic dissociation and can cause oxidative stress, in turn related to disease and ageing [62]. Additionally, $\mathrm{O}_{2}$ deprivation can affect synaptic transmission and ultimately cause cell death by cytosolic accumulation of calcium ions $\left(\mathrm{Ca}^{2+} ;[63]\right)$. The gene rph3a (see Additional file 1: Table S1) is a candidate gene under positive selection that could be related to redox processes. It is involved in the regulation of synaptic vesicle traffic that mediates the release of a neurotransmitter when $\mathrm{Ca}^{2+}$ cytosolic levels rise (GO:0048854: calcium ion-regulated exocytosis of neurotransmitter). Redox processes innovations might have contributed to the development of better protective mechanisms to increased cytotoxic threats in the edaphic atmosphere. Similar adaptations have been reported in the most studied fossorial mammal: the naked mole-rat Heterocephalus glaber Rüppell, 1842, where hypoxia experiments have revealed an attenuation of the accumulation of intracellular calcium [64] and the importance of redox processes $[65,66]$ during $\mathrm{O}_{2}$ deprivation. Naked mole rats have a surprisingly low metabolic rate in comparison with other mammals. Caecilians also maintain a low metabolism, notably lowest among extant amphibian groups $[67,68]$.

\section{Evolvability in Teresomata ancestors}

After the colonization of surface soil habitats and initial diversification of caecilians, the origin of the Teresomata probably involved colonisation of and adaptation to deeper soil habitats and a second wave of ecological opportunity. Several major events in caecilian evolution occurred along the Teresomata branch (branch 2 in Fig. $1)$, including the loss of a free-living larval stage and the origin of maternal feeding [69]. Given that number of evolutionary changes, surprisingly only eight genes were found with signatures of positive selection. Some of these genes were associated with different GO terms including redox processes (see Additional file 1: Table S1 and Fig. 2). Given that gas exchange $\left(\mathrm{O}_{2}\right.$ and $\left.\mathrm{CO}_{2}\right)$ becomes increasingly hampered deeper within soils, redox processes innovations, in this case by changes in the aoc3 gene (candidate gene under positive selection in the Teresomata branch), might have helped caecilians to cope with the more and more extreme conditions in this habitat. The highlighted gene (aoc3) encodes vascular adhesion protein 1 , whose expression increases under hypoxia [70].

Within Teresomata, a major ecological shift occurred in the sampled evolutionary tree along the terminal branch subtending T. compressicauda (branch 8 in Fig. 1 ), with the evolution of fully aquatic adults and viviparity. Among the genes identified on the T. compressicauda, the gene fam13a is involved in signal transduction (GO:0007165) and has been related to different lung diseases $[71,72]$ with its activity induced by low levels of $\mathrm{O}_{2}$ [73]. While cutaneous gas exchange is important in Amphibia [74], T. compressicauda has the largest lungs of any caecilian [75], is reported to have more than $90 \%$ pulmonary oxygen uptake [76], and is able to tolerate hypoxic and hypercapnic conditions [77]. 
Thus, changes in fam13a might be related to enhanced pulmonary function.

\section{The expert burrowers}

The genus Microcaecilia Taylor, 1968 with 14 described species so far (two sampled in our study, M. unicolor and $M$. dermatophaga) is the most speciose genus of caecilians after Ichthyophis Fitzinger, 1826 (50 species) and Caecilia Linnaeus, 1758 (34 species). Microcaecilia have bullet shaped heads and heavily ossified skulls with prominent snouts and rudimentary eyes that are covered by bone [78]. They are the most dedicated burrowers among our sampled taxa. This more extreme fossoriality perhaps led to another wave of ecological opportunity for caecilian radiation. Among the genes found under positive selection on the Microcaecilia branch, the gene pinx1 inhibits telomere elongation (GO:0010521: telomerase inhibitor activity; GO:0051974: negative regulation of telomerase activity; GO:0003676: nucleic acid binding; [79]) and has been related to aging, also found to have been under positive selection in a study of molecular adaptations to fossorial life in African mole-rats [47]. Changes in pinx 1 might be an indication of a relatively extended lifespan in Microcaecilia compared to other amphibians, as in mole-rats among mammals. However, little is known about longevity in caecilians, especially in the wild [80].

Another gene inferred to have been under positive selection along the Microcaecilia branch that drew our attention is linked to pigmentation by the GO term GO:0043473. This protein-coding gene is annotated as a tetraspanin (tspan36, see Additional file 1: Table S1). Tetraspanins are a large family of transmembrane proteins (38 homologous genes in vertebrates) that are involved in diverse biological processes, acting as organizers in the membranes of many kinds of animal cells [81]. The functions of all the tetraspanins are not well known, but some members of this gene family have been associated with pigment cell interactions and pigment pattern formation [82]. The tspan36 gene seems to play an important role in melanocyte biology [83]. Despite spending all or most of their lives in soil, many caecilian species are pigmented, and some are brightly coloured and visually striking, perhaps aposematically in some cases [84], although many are also more drably coloured. Adaptive innovation in tspan36 might be related to evolutionary changes in pigmentation. Species of Microcaecilia have a range of colours and patterns [85] and the ancestral phenotype is currently unclear.

\section{Other specific traits}

Unlike other extant amphibians, many caecilian amphibians have collagenous scales hidden in annular folds in the skin, the function of which is unknown [86, 87]. Some ancestors of caecilians are expected to have had scales over the entire external surface of the body rather than embedded in the skin. The peculiar disposition (when present) of scales within the skin in modern caecilians and their varied patterns of reduction and loss are derived traits plausibly associated with the evolution of a burrowing habit. In extant caecilians, scales are diverse in their number, form and distribution along the body with each of our sampled species presenting a distinct pattern. Collagen chains are structural proteins classified under different types, and they are the main components of skin, connective tissues, bone, teeth and epithelia [88]. We hypothesise that some of the collagen protein-coding genes might code for collagen chains involved in the formation of caecilian scales, particularly col17a1 that presented a positive selection signature on the Gymnophiona branch and skin tissue specificity expression. We are aware that collagen chains are involved in many other important biological processes, for instance col4a2 is part of the ECM-receptor interaction pathway on the Gymnophiona branch. Also, one of the candidate collagen genes under positive selection is found in the branch subtending $T$. compressicauda (col4a1), a species that lacks annular scales. Mutations in different genes of type IV collagen cause the Alport syndrome in humans, characterized by hearing and eyesight loss among other symptoms [89].

Lipid metabolism and fatty acid metabolism are biological processes associated with several of the genes that bear evidence of positive selection. Lipids have very diverse biological functions and play important roles such as energy storage, signaling, and formation of barriers in the cell membrane. They are also involved in other vital and apomorphic roles in caecilians, including the provision of nutrition to large yolky eggs in oviparous taxa, and to developing fetuses and/or newborns during oviductal and/or skin feeding among teresomatan caecilians [90, 91]. Some of these genes might be related to the synthesis, transformation and/or storage of lipids for these traits. For instance, some of these genes have been found expressed in the yolk of zebrafish (elovl5; [92]), in mouse embryoid bodies (cers6; [93]), and during vitellogenesis in teleost fish (cyp17a1; [94]).

Some of the candidate positively selected genes have different important roles linked to the immune system, for example tet 2 is expressed in T cells [95], masp1 presents multiple roles in the innate immune response (masp1; [96]), enpp3 regulates allergic responses [97], and fyn controls immune receptor signaling status [98]. Innovations in immune system genes within Gymnophiona are unsurprising. The innate amphibian immune system is likely under strong selective pressure, evolving in arms races via interactions with pathogens. The vast majority of adult caecilians live with their bodies in close proximity to moist (probably microbially rich) tropical 
soil substrates, and it can be expected that the ecomorphological disparity of caecilians relative to their closest relatives and their ecological diversity promoted immunological molecular genetic changes within the group. Amphibians, survivors of the Earth's last four mass extinction events, are facing an unprecedentedly high risk of extinction that seems to be linked, in part, to challenges to their immune systems $[99,100]$. Caecilian conservation biology is very poorly understood [101] and immune system mechanisms are in need of better understanding.

\section{Conclusions}

Molecular adaptive changes in caecilian amphibians are found to be associated mostly with protein-coding gene products with membrane or extracellular location. These genes present low levels of conservation and connectivity (no PPIs and only one functional network were found). The 168 genes that we infer to have been under positive selection are candidate genes with potential to further clarify adaptations of caecilians linked to their unique and variable natural histories. Several of these candidate genes are possibly causally related to differing degrees of fossoriality and hypothesized ecological shifts that might each have led to new ecological opportunities. Experiments (e.g. transfecting cell-lines with a candidate gene and in silico reconstructions of the protein structure) are required to test the function of these protein-coding genes and to identify their particular roles in important processes, such as perception, reduction-oxidation, and aging in caecilians. Functional experiments can be prompted and focused based on genome-wide studies that have narrowed down candidate genes for more thorough investigation. In this study, we identify a set of candidate genes plausibly involved in ecological and evolutionary key processes. Much biological research relies upon a small number of animal models to investigate biological processes but insights from a broader spectrum of organismal diversity, especially from neglected taxa such as caecilians, are also helpful [102].

The inclusion of representatives of additional caecilian lineages in future studies (especially to expand the phylogenetic, ecological, and geographic sampling), and more complete sets of genes from the sampled species (available transcriptome data thus far corresponds mostly to adult animals, [40]) could provide further insights into the selective pressures shaping caecilian molecular evolution. Adaptations are not necessarily only associated with positive selection in protein-coding genes. Changes in regulation can also allow adaptation to new environments, and are thus far unexplored for caecilians. The findings reported here will hopefully provide a foundation for further analyses of the molecular bases of the radiation of Gymnophiona and of molecular evolution in vertebrates more generally.

\section{Methods}

\section{Genomic data}

The source data of this study were the protein-coding gene sequences (both nucleotide and amino-acid level) from reference transcriptomes of five caecilian species $(R$. bivittatum, C. tentaculata, T. compressicauda, M. unicolor and $M$. dermatophaga; assemblies are available from NCBI through BioProject ID number PRJNA387587; [40]) as well as those for the frog $X$. tropicalis, the only amphibian currently represented in the Ensembl database [103]. Species-specific caecilian transcriptomes were de novo assembled from paired-end RNA-seq samples of multiple tissues (kidney, liver, and skin samples for each of the five species plus a selection of other tissues for subsets of the five species: foregut, heart, lung, muscle, spleen, and testis) yielding five reference transcriptomes with a high percentage of completeness. Protein-coding sequences were identified from these assembled sequences with an open reading frame [40]. For each $X$. tropicalis gene, the isoform encoding the longest protein was chosen for analysis, and BLAST searches (blastp tool, version 2.2.28; E-value $<10^{-10}$; [104]) were conducted against the proteins of each of the caecilian transcriptomes. Likewise, each caecilian protein sequence was used as a query in a BLAST search against the $X$. tropicalis proteome. Pairs of best reciprocal hits were considered orthologs. Only $X$. tropicalis genes with putative orthologs in all five caecilian species were used in downstream analyses.

For each group of orthologs, the inferred amino acid sequences were aligned using PRANK with default parameters [105]. Given the sensitivity of positive selection analyses to alignment errors, we carried out a thorough filtering of the alignments. First, Gblocks version 0.91b [106] with default settings was used to remove problematic regions. Second, two ad hoc sliding window filters (of 15 and 5 residues) were used to eliminate regions coding for amino acids that are unique to one species (with 10 or more amino acid singletons, or where all five were singletons, respectively; as in as in $[107,108]$ ) because such regions are often associated with annotation or sequencing errors. The resulting amino acid sequence alignments were used to guide the alignment of the corresponding codon sequences.

\section{Tests of positive selection}

To infer positive selection, we performed branch-site model tests $[109,110]$ for every group of orthologous genes and for every branch of the studied subset of the caecilian phylogeny (based on [40, 69]; Fig. 1), excluding the $X$. tropicalis branch, and computing branch lengths each time for each group of genes using the CODEML program in PAML 4.6 [111]. The branch-site model test (model A vs. null model A) assumes that only a fraction of sites might have undergone positive selection and 
only along a single a priori identified branch (foreground lineage) on the phylogeny. The test assumes four classes of sites: codons that are conserved $(\omega<1)$, codons that are evolving neutrally $(\omega=1)$, and codons under positive selection $(\omega>1)$ on the foreground branch but conserved (2a) or neutral (2b) on the other (background) branches. Model A was implemented with the default starting value (0.4) for $\omega$ (model $=2$, NSsites $=2$, cleandata $=1$ and fix_blength $=0$ ) and used as the alternative hypothesis for the Likelihood Ratio Test (LRT). The null model of the LRTs was the null model A with only one change in the parameters from model A: $\omega$ fixed at 1 for sites under positive selection on the foreground branch (2a and $2 \mathrm{~b}$ sites). P-values for the LRTs were computed using the $x^{2}$ distribution with one degree of freedom, and divided by two [111, 112]. Multiple-testing corrections were conducted following Benjamini and Hochberg's method in order to control for a false discovery rate (FDR) using $\mathrm{R}$ [113]. Genes with a q-value $<0.1$ and $\omega>1$ for the foreground branch ( $2 \mathrm{a}$ and $2 \mathrm{~b}$ sites) were interpreted as being genes under positive selection. Sites under positive selection were identified by computing posterior probabilities using the Bayes empirical Bayes (BEB) approach [114]. To obtain an estimation of the proportion of tandem complex mutations in our results, we analysed the position of the codons under positive selection from BEB test outputs. Also, the suitability of the positive selection analyses for the multiple sequence alignments of the genes with signatures of selection was tested using the GUIDANCE2 methodology [44], computing the GUIDANCE alignment score for each inference (alignments are available from the Github repository: TorresSanchezM/alignments). The number of genes with signatures of positive selection in sister branches were compared by two-tailed binomial tests under the hypothesis of equal probability of being or not under positive selection $(p=0.5)$ with a $95 \%$ confidence level.

\section{Functional annotation}

For each of the putative orthologous groups inferred to be under positive selection, we obtained the associated GO terms from the $X$. tropicalis annotation using the BioMart data-mining tool (Ensembl Genes 95, Xenopus genes JGI 4.2; [103]). Novel or uncharacterised genes from $X$. tropicalis were annotated by BLAST searches (blastx tool; [104]) against the Non-redundant protein sequences database. We summarized and visualized the common GO terms of the selected genes and their frequencies of occurrence using REVIGO [43] applying $0.7 \%$ allowed similarity (by the semantic similarity method) and using the whole UniProt database [115] to define the size of each GO term. The exploratory REVIGO networks were manually processed to build a unique explanatory plot with general GO categories presented in the REVIGO networks for each of the nine analysed branches. Enrichment analysis for each branch was performed using the GO enrichment analysis tool [116]. Additionally, protein-protein interactions (PPIs) were inferred using STRING [117] with $X$. tropicalis as the reference organism and default settings, comparing the interactions of caecilian protein-coding genes on each branch among themselves to a random set of proteins of similar size, drawn from the chosen genome. Finally, after counting Transcripts Per Million (TPM) units with the RSEM program [118] for each gene under positive selection in the caecilian transcriptomes, gene-expression presence across tissues was determined for cases with more than $5 \%$ of the total TPM being found in one tissue type. Tissue specificity was identified when more than $95 \%$ of the total TPM were found in one particular tissue type (following [40]).

\section{Additional file}

Additional file 1: Table S1. Description of genes inferred to have been under positive selection in caecilian evolution $\left(\omega{ }^{*}\right.$ for sites under positive selection on the foreground branch, $2 \mathrm{a}$ and $2 \mathrm{~b}$ sites; $\mathrm{NR}$ database $=$ Non redundant protein database; $F=$ foregut; $H=$ heart; $K=$ kidney; $L=$ liver; $\mathrm{Lu}=$ lung; $\mathrm{M}=$ muscle; $\mathrm{S}=$ skin; $\mathrm{Sp}=$ spleen; $\mathrm{T}=$ testis). (PDF $300 \mathrm{~kb}$ )

\section{Abbreviations \\ BEB: Bayes empirical Bayes; dN: Non-synonymous nucleotide substitutions; dS: Synonymous nucleotide substitutions; ECM: Extracellular matrix; FDR: False discovery rate; GO: Gene ontology; LRT: Likelihood ratio test; PPIs: Protein-protein interactions; TPM: Transcripts Per Million}

\section{Acknowledgements}

We thank Iván de la Hera, José A. Díaz, Karen Siu-Ting, David Buckley, Iván Gómez-Mestre, Antonio González-Martín, Javier Pérez-Tris, and Jeff Streicher for insightful comments and advice. Computational analyses were performed at the Altamira HPC cluster of the Institute of Physics of Cantabria (IFCA(SIC), which is part of the Spanish Supercomputing Network. We thank Myrian Virevaire (Direction de l'Environment de l'Amenagement et du Logement) and Le Comitee Scientifique Regional du Patrimonie Naturel for supporting facilitating fieldwork in French Guiana.

\section{Funding}

This study was financially supported by the Spanish Ministry of Economy and Competitiveness (MINECO: RYC-2011-09321 and CGL2012-40082 grants to DSM; BES-2013-062723 FPI predoctoral fellowship, EEBB-I-16-11395 and EEBBI-17-12039 research stays to MTS). The MINECO also provided support through AdaptNET project (CGL2015-71726-REDT grant). DAP was supported by the National Science Foundation and National Institutes of Health (MCB 1818288, P20GM103440 and 5P30GM110767-04 grants). The funding bodies had no role in the design of the study, the collection, analysis, the interpretation of data or the writing of the manuscript.

\section{Availability of data and materials}

Not applicable.

\section{Authors' contributions}

DJG, CJC, MW and DSM devised the conceptual project. MTS, DJG and MW designed the study. MTS and DAP analyzed the data. MTS wrote the manuscript with the contribution of DJG, DAP, CJC, MW, and DSM in the interpretation of results and discussion on principle findings. All authors read and approved the final manuscript. 


\section{Ethics approval and consent to participate}

Not applicable.

\section{Consent for publication}

Not applicable.

\section{Competing interests}

The authors declare that they have no competing interests.

\section{Publisher's Note}

Springer Nature remains neutral with regard to jurisdictional claims in published maps and institutional affiliations.

\section{Author details}

'Department of Biodiversity, Ecology and Evolution, Complutense University of Madrid, 28040 Madrid, Spain. ${ }^{2}$ Present address: Department of Neuroscience, Spinal Cord and Brain Injury Research Center \& Ambystoma Genetic Stock Center, University of Kentucky, Lexington, KY 40536, USA. ${ }^{3}$ Department of Life Sciences, The Natural History Museum, London SW7 5BD, UK. ${ }^{4}$ Department of Biology, University of Nevada, Reno, NV 89557, USA. ${ }^{5}$ Institute for Global Food Security, Queen's University Belfast, University Road, Belfast BT7 1NN, Northern Ireland, UK.

\section{Received: 12 March 2019 Accepted: 15 April 2019}

\section{Published online: 09 May 2019}

\section{References}

1. Darwin C. On the origin of species. 6th ed. London: John Murray; 1859.

2. Simpson GG. The major features of evolution. New York: Columbia University Press; 1953.

3. Schluter D. The ecology of adaptive radiation. Oxford: Oxford Univ. Press; 2000.

4. Givnish TJ. 1997. Adaptive radiation and molecular systematics: issues and approaches. See Givnish \& Sytsma 1997, pp. 1-54.

5. Losos JB, Mahler DL. 2010. Adaptive radiation: the interaction of ecological opportunity, adaptation, and speciation. In Evolution since Darwin: The First 150 Years, ed. MA Bell, DJ Futuyma, WF Eanes, JS Levinton, pp. 381-420. Sunderland, MA: Sinauer.

6. Yoder JB, Clancey E, Des Roches S, Eastman JM, Gentry L, Godsoe W, Hagey TJ, Jochimsen D, Oswald BP, Robertson J, et al. Ecological opportunity and the origin of adaptive radiations. J Evol Biol. 2010;23:1581-96.

7. Wellborn GA, Langerhans RB. Ecological opportunity and the adaptive diversification of lineages. Ecol Evol. 2015;5:176-95.

8. Stroud JT, Losos JB. Ecological opportunity and adaptive radiation. Annu Rev Ecol Evol Syst. 2016;47:507-32.

9. Bergthorsson U, Andersson DI, Roth JR. Ohno's dilemma: evolution of new genes under continuous selection. Proc Natl Acad Sci U S A. 2007;104: 17004-9.

10. Conant GC, Wolfe KH. Turning a hobby into a job: how duplicated genes find new functions. Nat Rev Genet. 2008:9:938-50.

11. Wagner A. The molecular origins of evolutionary innovations. Trends Genet. 2011;27:397-410

12. Yang Z. Adaptive Molecular Evolution. In: Handbook of statistical genetics, vol. 1. 3rd ed; 2008. p. 375-406

13. Ohno S. Evolution by gene duplication. New York: Springer-Verlag; 1970.

14. Meyer A, Schartl M. Gene and genome duplications in vertebrates: the oneto-four (-to-eight in fish) rule and the evolution of novel gene functions. Curr Opin Cell Biol. 1999;11:699-704.

15. Taylor JS, Raes J. Duplication and divergence: the evolution of new genes and old ideas. Annu Rev Genet. 2004;38:615-43.

16. Moreira FMS, Huising EJ, Bignell DE, Senwo Z. A handbook of tropical soil biology: Sampling \& Characterization of below-ground biodiversity. Soil Sci Soc Am J. 2012;76:309.

17. Nevo E. Adaptive convergence and divergence of subterranean mammals. Annu Rev Ecol Syst. 1979;10:269-308.

18. Wake M. H. 1993. The skull as a locomotor organ. In: Hanken J and BKH eds 1993. The skull: functional and evolutionary mechanisms. Univ Chicago press:422-453

19. Roscito JG, Rodrigues MT. Comparative cranial osteology of fossorial lizards from the tribe Gymnophthalmini (Squamata, Gymnophthalmidae). J Morphol. 2010;271:1352-65.
20. Zhang P, Wake DB. Higher-level salamander relationships and divergence dates inferred from complete mitochondrial genomes. Mol Phylogenet Evol. 2009;53:492-508.

21. Irisarri I, Baurain D, Brinkmann H, Delsuc F, Sire JY, Kupfer A, Petersen J, Jarek M, Meyer A, Vences M, et al. Phylotranscriptomic consolidation of the jawed vertebrate timetree. Nat Ecol Evol. 2017;1:1370-8.

22. Wells KD. 2008. The ecology and behavior of amphibians. Chicago (Illinois): University of Chicago Press.

23. Székely $D$, Cogălniceanu $D$, Székely $P$, Denoël $M$. Dryness affects burrowing depth in a semi-fossorial amphibian. J Arid Environ. 2018;155:79-81.

24. Wilkinson M. Caecilians. Curr Biol. 2012;22.

25. Grant BR, Grant PR. Darwin's finches: population variation and sympatric speciation. Natl Acad Sci. 1979;76:2359-63.

26. Gillespie R. Community assembly through adaptive radiation in Hawaiian spiders. Science. 2004:303(5656):356-9.

27. Givnish TJ, Millam KC, Mast AR, Paterson TB, Theim TJ, Hipp AL, Henss JM, Smith JF, Wood KR, Sytsma KJ. Origin, adaptive radiation and diversification of the Hawaiian lobeliads (Asterales: Campanulaceae). Proc R Soc B Biol Sci. 2009:276:407-16.

28. Losos JB. Lizards in an evolutionary tree: ecology and adaptive radiation of anoles. Berkeley: Univ. Calif. Press; 2009.

29. Seehausen O. African cichlid fish: a model system in adaptive radiation research. Proc R Soc B Biol Sci. 2006;273:1987-98.

30. Sturmbauer C, Husemann M, Danley PD. 2011. Explosive speciation and adaptive radiation of east African cichlid fishes. In: Biodiversity hotspots distribution and protection of conservation priority areas. p. 333-362 STExplosive speciation and adaptive radiation.

31. McGowan AJ. Ammonoid taxonomic and morphologic recovery patterns after the Permian-Triassic. Geology. 2004;32:665-8.

32. Hull P. Life in the aftermath of mass extinctions. Curr Biol. 2015;25:R941-52.

33. Wu T, Ayres E, Bardgett RD, Wall DH, Garey JR. Molecular study of worldwide distribution and diversity of soil animals. Proc Natl Acad Sci U S A. 2011;108:17720-5

34. Sherratt E, Gower DJ, Klingenberg CP, Wilkinson M. Evolution of cranial shape in caecilians (Amphibia: Gymnophiona). Evol Biol. 2014;41:528-45.

35. Naylor BG, Nussbaum RA. The trunk musculature of caecilians (Amphibia: Gymnophiona). J Morphol. 1980;166:259-73.

36. O'Reilly JC, Summers AP, D a R. The evolution of the functional role of trunk muscles during locomotion in adult amphibians. Am Zool. 2000;40:123-35.

37. Wake $\mathrm{MH}$. The comparative morphology and evolution of the eyes of caecilians (Amphibia, Gymnophiona). Zoomorphology. 1985;105:277-95.

38. Wilkinson M, Garbout A, \& Mohun SM. 2018. The visual system of caecilian amphibians. Integr Comp Biol. 58: E252-E252.

39. Maddin HC, Sherratt E. Influence of fossoriality on inner ear morphology: insights from caecilian amphibians. J Anat. 2014;225:83-93.

40. Torres-Sánchez M, Creevey CJ, Kornobis E, Gower DJ, Wilkinson M, San Mauro D. Multi-tissue transcriptomes of caecilian amphibians highlight incomplete knowledge of vertebrate gene families. DNA Res. 2019;26:13-20.

41. Wilkinson M, San Mauro D, Sherratt E, Gower DJ. A nine-family classicification of caecilians (Amphibia: Gymnophiona). Zootaxa. 2011;2874 41-64.

42. Kamei RG, San Mauro D, Gower DJ, Van Bocxlaer I, Sherratt E, Thomas A, Babu S, Bossuyt F, Wilkinson M, Biju SD. Discovery of a new family of amphibians from Northeast India with ancient links to Africa. Proc R Soc B Biol Sci. 2012:279:2396-401.

43. Supek F, Bošnjak M, Škunca N, Šmuc T. Revigo summarizes and visualizes long lists of gene ontology terms. PLoS One. 2011;6.

44. Sela I, Ashkenazy H, Katoh K, Pupko T. GUIDANCE2: accurate detection of unreliable alignment regions accounting for the uncertainty of multiple parameters. Nucleic Acids Res. 2015:43:W7-14.

45. Kosiol C, Vinař T, Da Fonseca RR, Hubisz MJ, Bustamante CD, Nielsen R, Siepel A. Patterns of positive selection in six mammalian genomes. PLoS Genet. 2008;4:e1000144.

46. Roux J, Privman E, Moretti S, Daub JT, Robinson-Rechavi M, Keller L. Patterns of positive selection in seven ant genomes. Mol Biol Evol. 2014;31:1661-85.

47. Davies KTJ, Bennett NC, Tsagkogeorga G, Rossiter SJ, Faulkes CG. Family wide molecular adaptations to underground life in African mole-rats revealed by phylogenomic analysis. Mol Biol Evol. 2015:32:3089-107.

48. Anisimova M, Yang Z. Multiple hypothesis testing to detect lineages under positive selection that affects only a few sites. Mol Biol Evol. 2007:24:1219-28. 
49. Diekmann Y, Pereira-Leal JB. Gene tree affects inference of sites under selection by the branch-site test of positive selection. Evol Bioinforma. 2016; 11:11-7.

50. Gharib WH, Robinson-Rechavi M. The branch-site test of positive selection is surprisingly robust but lacks power under synonymous substitution saturation and variation in GC. Mol Biol Evol. 2013;30:1675-86.

51. Kim PM, Korbel JO, Gerstein MB. Positive selection at the protein network periphery: evaluation in terms of structural constraints and cellular context. Proc Natl Acad Sci U S A. 2007;104:20274-9.

52. Montoya-Burgos Jl. Patterns of positive selection and neutral evolution in the protein-coding genes of Tetraodon and Takifugu. PLoS One. 2011;6.

53. Lowe CB, Kellis M, Siepel A, Raney BJ, Clamp M, Salama SR, Kingsley DM, Lindblad-Toh K, Haussler D. Three periods of regulatory innovation during vertebrate evolution. Science. 2011;333:1019-24.

54. Shim C, Kwon HB, Kim K. Differential expression of laminin chain-specific mRNA transcripts during mouse preimplantation embryo development. Mol Reprod Dev. 1996:44:44-55.

55. Smyth N, Vatansever SH, Murray P, Meyer M, Frie C, Paulsson M, Edgar D. Absence of basement membranes after targeting the LAMC1 gene results in embryonic lethality due to failure of endoderm differentiation. J Cell Biol. 1999;144:151-60.

56. Murray $P$, Edgar D. Regulation of programmed cell death by basement membranes in embryonic development. J Cell Biol. 2000;150:1215-21.

57. Rayagiri SS, Ranaldi D, Raven A, Mohamad Azhar NIF, Lefebvre O, Zammit PS, Borycki AG. Basal lamina remodeling at the skeletal muscle stem cell niche mediates stem cell self-renewal. Nat Commun. 2018;9.

58. Matern MS, Beirl A, Ogawa Y, Song Y, Paladugu N, Kindt KS, Hertzano R. Transcriptomic profiling of zebrafish hair cells using RiboTag. Front Cell Dev Biol. 2018;6:47

59. Parker J, Tsagkogeorga G, Cotton JA, Liu Y, Provero P, Stupka E, Rossiter SJ. Genome-wide signatures of convergent evolution in echolocating mammals. Nature. 2013;502:228-31.

60. Mohun SM, Davies WL, Bowmaker JK, Pisani D, Himstedt W, Gower DJ, et al. Identification and characterization of visual pigments in caecilians (Amphibia: Gymnophiona), an order of limbless vertebrates with rudimentary eyes. J Exp Biol. 2010;213(20):3586-92.

61. LeGates TA, Fernandez DC, Hattar S. Light as a central modulator of circadian rhythms, sleep and affect. Nat Rev Neurosci. 2014;15:443-54

62. Davalli P, Mitic T, Caporali A, Lauriola A, D'Arca D. ROS, cell senescence, and novel molecular mechanisms in aging and age-related diseases. Oxidative Med Cell Longev. 2016;2016.

63. Bhosale G, Sharpe JA, Sundier SY, Duchen MR. Calcium signaling as a mediator of cell energy demand and a trigger to cell death. Ann N Y Acad Sci. 2015:1350:107-16.

64. Peterson BL, Larson J, Buffenstein R, Park TJ, Fall CP. Blunted neuronal calcium response to hypoxia in naked mole-rat hippocampus. PLoS One. 2012;7.

65. Kim EB, Fang X, Fushan AA, Huang Z, Lobanov AV, Han L, Marino SM, Sun X, Turanov AA, Yang $P$, et al. Genome sequencing reveals insights into physiology and longevity of the naked mole rat. Nature. 2011;479:223-7.

66. Fang X, Nevo E, Han L, Levanon EY, Zhao J, Avivi A, Larkin D, Jiang X, Feranchuk S, Zhu Y, et al. Genome-wide adaptive complexes to underground stresses in blind mole rats Spalax. Nat Commun. 2014;5:3966.

67. Steele WK, Louw GN. Caecilians exhibit cutaneous respiration and high evaporative water loss. South African J Zool. 1988:23:134-5.

68. Smits AW, Flanagin J. Bimodal respiration in aquatic and terrestrial apodan amphibians. Integr Comp Biol. 1994;34(2):247-63.

69. San Mauro D, Gower DJ, Müller H, Loader SP, Zardoya R, Nussbaum RA, Wilkinson M. Life-history evolution and mitogenomic phylogeny of caecilian amphibians. Mol Phylogenet Evol. 2014;73:177-89.

70. Zhang Y, Yi W, Yao J, Yu X, Qian C, Hu Z. Hypoxia serves a key function in the upregulated expression of vascular adhesion protein-1 in vitro and in a rat model of hemorrhagic shock. Mol Med Rep. 2017;16:1189-99.

71. Cho MH, Boutaoui N, Klanderman BJ, Sylvia JS, Ziniti JP, Hersh CP, Demeo DL, Hunninghake GM, Litonjua AA, Sparrow D, et al. Variants in FAM13A are associated with chronic obstructive pulmonary disease. Nat Genet. 2010;42: 200-2.

72. Ziółkowska-Suchanek I, Mosor M, Gabryel P, Grabicki M, Zurawek M, Fichna M, Strauss E, Batura-Gabryel H, Dyszkiewicz W, Nowak J. Susceptibility loci in lung cancer and COPD: association of IREB2 and FAM13A with pulmonary diseases. Sci Rep. 2015;5.
73. Ziółkowska-Suchanek I, Mosor M, Podralska M, Izykowska K, Gabryel P, Dyszkiewicz W, Słomski R, Nowak J. FAM13A as a novel hypoxia-induced gene in non-small cell lung cancer. J Cancer. 2017;8:3933-8.

74. Nussbaum RA, Wilkinson M. A new genus of lungless tetrapod: a radically divergent caecilian (Amphibia: Gymnophiona). Proc R Soc B Biol Sci. 1995; 261:331-5.

75. Wilkinson M, Nussbaum RA. Comparative morphology and evolution of the lungless caecilian Atretochoana eiselti (Taylor) (Amphibia: Gymnophiona: Typhlonectidae). Biol J Linn Soc. 1997;62:39-109.

76. Sawaya P. Metabolismo respiratorio de anfibio gymnophiona, Typhlonectes compressicauda. Bol Fac Filos Cienc Letras Univ San Paulo Ser Zool. 1947;12:51-6.

77. Toews D, Macintyre D. Blood respiratory properties of a viviparous amphibian. Nature. 1977;266:464-5.

78. Renous S. Cranial morphology of an American siphonopid, Microcaecilia unicolor (Amphibia, Gymnophiona) and its functional interpretation. Gegenbaurs Morphol Jahrb. 1990;136:781-806

79. Zhou XZ, Lu KP. The Pin2/TRF1-interacting protein PinX1 is a potent telomerase inhibitor. Cell. 2001;107:347-59.

80. De Magalhães JP, Costa J. A database of vertebrate longevity records and their relation to other life-history traits. J Evol Biol. 2009;22:1770-4.

81. Hemler ME. Tetraspanin functions and associated microdomains. Nat Rev Mol Cell Biol. 2005;6:801-11.

82. Inoue S, Kondo S, Parichy DM, Watanabe M. Tetraspanin 3c requirement for pigment cell interactions and boundary formation in zebrafish adult pigment stripes. Pigment Cell Melanoma Res. 2014;27:190-200.

83. Lapedriza A. 2015. Gene regulatory network of melanocyte development. PhD University of Bath.

84. Wollenberg KC, John Measey G. Why colour in subterranean vertebrates? Exploring the evolution of colour patterns in caecilian amphibians. J Evol Biol. 2009:22:1046-56.

85. Wilkinson M, Sherratt E, Starace F, Gower DJ. A new species of skin-feeding caecilian and the first report of reproductive mode in Microcaecilia (Amphibia: Gymnophiona: Siphonopidae). PLoS One. 2013;8.

86. Taylor EH. Squamation in caecilians, with an atlas of scales. The University of Kansas. Scie Bull. 1972;49:989-1164.

87. Zylberberg L, Castanet J, De Ricqles A. Structure of the dermal scales in Gymnophiona (Amphibia). J Morphol. 1980;165:41-54.

88. Lodish H, Berk A, Zipursky S. 2000. Collagen: The fibrous Proteins of the Matrix In: Molecular Cell Biology p Section 22.3.

89. Lemmink HH, Mochlzukj T, Van Den Heuvel, LP w j, Schröder $\mathrm{CH}$, Barrientos A, Monnens LAH, Van Oost BA, Brunner HG, Reeders ST, Smeets HJM. Mutations in the type IV collagen a3 (COL4A3) gene in autosomal recessive alport syndrome. Hum Mol Genet. 1994;3:1269-73.

90. Kupfer A, Müller H, Antoniazzi MM, Jared C, Greven H, Nussbaum RA, Wilkinson M. Parental investment by skin feeding in a caecilian amphibian. Nature. 2006;440:926-9.

91. Wilkinson M, Kupfer A, Marques-Porto R, Jeffkins H, Antoniazzi MM, Jared C. One hundred million years of skin feeding? Extended parental care in a Neotropical caecilian (Amphibia: Gymnophiona). Biol Lett. 2008:4:358-61.

92. Fraher D, Sanigorski A, Mellett NA, Meikle PJ, Sinclair AJ, Gibert Y. Zebrafish embryonic Lipidomic analysis reveals that the yolk cell is metabolically active in processing lipid. Cell Rep. 2016;14:1317-29.

93. Park $H$, Haynes CA, Nairn AV, Kulik M, Dalton S, Moremen K, Merrill AH. Transcript profiling and lipidomic analysis of ceramide subspecies in mouse embryonic stem cells and embryoid bodies. J Lipid Res. 2010;51: 480-9.

94. Lubzens E, Bobe J, Young G, Sullivan CV. Maternal investment in fish oocytes and eggs: the molecular cargo and its contributions to fertility and early development. Aquaculture. 2017:472:107-43.

95. Zhong C, Zhu J. Tet2: breaking down barriers to T cell cytokine expression. Immunity. 2015:42:593-5.

96. Dobó J, Schroeder V, Jenny L, Cervenak L, Závodszky P, Gál P. Multiple roles of complement MASP-1 at the interface of innate immune response and coagulation. Mol Immunol. 2014;61:69-78.

97. Tsai SH, Kinoshita M, Kusu T, Kayama H, Okumura R, Ikeda K. The Ectoenzyme E-NPP3 negatively regulates ATP- dependent chronic allergic responses by basophils article the Ectoenzyme E-NPP3 negatively regulates ATP-dependent chronic allergic responses by basophils and Mast cells. Immunity. 2015;42(2):279-93.

98. Mkaddem SB, Murua A, Flament H, Titeca-Beauport D, Bounaix C, Danelli L, Launay P, Benhamou M, Blank U, Daugas E, et al. Lyn and Fyn function as 
molecular switches that control immunoreceptors to direct homeostasis or inflammation. Nat Commun. 2017;8.

99. Carey C, Cohen N, Rollins-Smith L. Amphibian declines: an immunological perspective. Dev Comp Immunol. 1999;23:459-72.

100. Collins JP, Storfer A. Global amphibian declines: sorting the hypotheses. Divers Distrib. 2003;9:89-98.

101. Gower DJ, Wilkinson M. Conservation biology of caecilian amphibians. Conserv Biol. 2005;19:45-55.

102. Sánchez Alvarado A. To solve old problems, study new research organisms. Dev Biol. 2018;433:111-4.

103. Yates A, Akanni W, Amode MR, Barrell D, Billis K, Carvalho-Silva D, Cummins C, Clapham P, Fitzgerald S, Gil L, et al. Ensembl 2016. Nucleic Acids Res. 2016:44:D710-6.

104. Altschul SF, Gish W, Miller WT, Myers EW, Lipman DJ. Basic local alignment search tool. J Mol Biol. 1990;215:403-10.

105. Löytynoja A. Phylogeny-aware alignment with PRANK. Methods Mol Biol. 2014;1079:155-70

106. Talavera G, Castresana J. Improvement of phylogenies after removing divergent and ambiguously aligned blocks from protein sequence alignments. Syst Biol. 2007;56:564-77.

107. Luisi P, Alvarez-Ponce D, Pybus M, Fares MA, Bertranpetit J, Laayouni H. Recent positive selection has acted on genes encoding proteins with more interactions within the whole human interactome. Genome Biol Evol. 2015; 7:1141-54.

108. Chakraborty S, Alvarez-Ponce D. Positive selection and centrality in the yeast and Fly protein-protein interaction networks. Biomed Res Int. 2016;2016.

109. Yang Z. Inference of selection from multiple species alignments. Curr Opin Genet Dev. 2002:12:688-94.

110. Zhang J, Nielsen R, Yang Z. Evaluation of an improved branch-site likelihood method for detecting positive selection at the molecular level. Mol Biol Evol. 2005;22:2472-9.

111. Yang Z. PAML 4: phylogenetic analysis by maximum likelihood. Mol Biol Evol. 2007:24:1586-91.

112. Yang Z, Dos Reis M. Statistical properties of the branch-site test of positive selection. Mol Biol Evol. 2011;28:1217-28.

113. R Development Core Team. 2016. R: A Language and Environment for Statistical Computing. R Found Stat Comput. Vienna Austria.

114. Yang Z, Wong WS, Nielsen R. Bayes empirical bayes inference of amino acid sites under positive selection. Mol Biol Evol. 2005:22:1107-18.

115. Apweiler R. UniProt: the universal protein knowledgebase. Nucleic Acids Res. 2004:1:D115-9.

116. The Gene Ontology Consortium. Gene ontology: tool for the unification of biology. Nat Genet. 2000;25:25-9.

117. Szklarczyk D, Franceschini A, Wyder S, Forslund K, Heller D, Huerta-Cepas J Simonovic M, Roth A, Santos A, Tsafou KP, et al. STRING v10: protein-protein interaction networks, integrated over the tree of life. Nucleic Acids Res. 2015;43:D447-52.

118. Li B, Dewey CN. RSEM: accurate transcript quantification from RNA-Seq data with or without a reference genome. BMC Bioinformatics. 2011;12:323.

Ready to submit your research? Choose BMC and benefit from:

- fast, convenient online submission

- thorough peer review by experienced researchers in your field

- rapid publication on acceptance

- support for research data, including large and complex data types

- gold Open Access which fosters wider collaboration and increased citations

- maximum visibility for your research: over $100 \mathrm{M}$ website views per year

At $\mathrm{BMC}$, research is always in progress.

Learn more biomedcentral.com/submissions 